\title{
Aa. Vv., «Cahiers de littérature française», I
}

\section{Marco Stupazzoni}

\section{OpenEdition}

\section{Journals}

\section{Edizione digitale}

URL: http://journals.openedition.org/studifrancesi/9273

DOI: ERREUR PDO dans /localdata/www-bin/Core/Core/Db/Db.class.php L.34 : SQLSTATE[HYO0O]

[2006] MySQL server has gone away

ISSN: 2421-5856

\section{Editore}

Rosenberg \& Sellier

\section{Edizione cartacea}

Data di pubblicazione: 1 juin 2008

Paginazione: 205

ISSN: 0039-2944

\section{Notizia bibliografica digitale}

Marco Stupazzoni, «Aa. VV., «Cahiers de littérature française», |», Studi Francesi [Online], 154 (LII | I) | 2008, online dal 30 novembre 2015, consultato il 07 janvier 2021. URL: http://

journals.openedition.org/studifrancesi/9273 ; DOI: https://doi.org/10.4000/studifrancesi.9273

Questo documento è stato generato automaticamente il 7 janvier 2021.

\section{(c) (i) (9)}

Studi Francesi è distribuita con Licenza Creative Commons Attribuzione - Non commerciale - Non opere derivate 4.0 Internazionale. 


\title{
Aa. Vv., «Cahiers de littérature française», I
}

\author{
Marco Stupazzoni
}

\section{NOTIZIA}

«Cahiers de littérature française», I, Università degli studi di Bergamo, Centro Arti Visive / Université Paris-Sorbonne, Centre de recherche sur la littérature française du XIX ${ }^{\mathrm{e}}$ siècle, janvier 2005.

1 Mariolina BERTINI (Balarouth: Balzac portraitiste en 1822, pp. 33-38) considera, riferendosi al romanzo giovanile balzachiano Une Heure de ma vie (febbraio-marzo 1822), il personaggio di Balarouth - il vagabondo che diventerà il fedele servitore e l'amico del romanziere - che prefigura alcune suggestive figure della Comédie humaine nelle quali è possibile scorgere la proiezione delle tensioni (tipicamente balzachiane) verso la ricerca e lo studio dell'uomo interiore. La sua connotazione grottesca ed eroicomica offre a Balzac «l'occasion d'une autoparodie, discrète mais délibérée, en accord parfait avec son modale, Sterne» (p. 37). Questo personaggio simbolico, conoscitore impareggiabile degli spazi parigini, saprà infondere a Balzac la propria energia vitale $\mathrm{e}$ il proprio sapere per poi essere dimenticato dallo scrittore che già, però, ne ha interiorizzato la scienza.

2 Francesco FIORENTINO (Province, mondanité, cohabitation. Note sur l'espace romanesque chez Balzac, pp. 71-82) studia, avvalendosi dell'esempio narrativo balzachiano, le «virtualités narratives» della dimensione spaziale, provinciale e parigina, intesa come «principe d'organisation de l'intrigue». Se la «stabilité ontologique» (p.73) del modello provinciale fornisce al romanzo balzachiano la "possibilité de créer un espace fermé et réglé où introduire le lecteur [...], où introduire l'intrigue» (p. 75), è nella dimensione circoscritta della mondanità che si manifesta «cet effet-province dans la vie parisienne» (p.76) inteso come spazio chiuso ed esclusivo animato soltanto dalla presenza e dal ritorno di determinate tipologie di personaggio. La terza forma di spazio 
romanzesco considerata dall'autore è quella dell'«espace en cohabitation» emblematicamente rappresentato dalla figura della portiera. Nel caso della pension Vauquer, ad esempio, la 'cohabitation' è un espediente narrativo che consente di rendere «vraisemblables des rencontres extraordinaires» creando una "atmosphère dépressive» e introducendo la «culture petite bourgeoise» (p. 80).

3 Sulle ambiguità letterarie e ideologiche proprie del personaggio principale de Illusion perdues, riflette Fabrice WILHELM (Lucien de Rubempré, objet d'envie, p. 127-141): a suo giudizio, questa figura, che è oggetto di una universale adulazione, non è altro che «l'illusion faite chair» (p. 132). La particolarità di Lucien, secondo l'autore, «est bien de posséder ces dons qui provoquent la violence passionnelle: qu'il s'agisse de jalousie envieuse ou d'une dévotion absolue mêlée d'addiction sexuelle, convoitise mortifère qui veut faire un avec l'objet pour se l'approprier et où l'on reconnaît l'envie sous le masque du désir, comme naguère sous celui de l'amitié» (p. 138). 